\title{
Regional Safety Issues: \\ Setting Goals, Information and Regulatory Support
}

\author{
$\underline{\text { Vladimir Moskvichev }}$
}

Institute of Computational Technologies SB RAS, Krasnoyarsk Branch Office, 660049, Krasnoyarsk, Russia

doi: https://doi.org/10.21467/abstracts.93.8

\begin{abstract}
ABSTRA C T
\end{abstract}
Problems and tasks. The problems of natural and technological safety of industrialized territories are caused by the destabilization processes in the system "society-technosphere-natural environment" and by ignoring the requirements of the sustainable development concept. The priority statement is the transition to the integrated support of natural and technological safety of individual territorial-industrial entities and regions. In conditions of intensive industrial development, a number of contradictions and features of this process arise:

- aggravation of the dilemma of scientific and technological progress: on the one hand - the high pace of development of the technosphere and outstanding achievements in various industries, and on the other hand - the emergence and growth of new threats to human, society, and the environment from technosphere objects;

- excessive exploitation of natural resources against the background of limited opportunities for their restoration and protection of the natural environment;

- insufficient regulatory framework to solve the problems of natural and technological safety at the state and regional levels;

- the impossibility of completely preventing man-made accidents and natural disasters that turned out to be unrecoverable in the past and cannot be excluded in the future (the concept of non-zero risk of accidents and disasters);

- in conditions of an increased level of risks and damage from the negative consequences of accidents and disasters, it is impossible to implement the concept of sustainable development of the regions;

- the most important components of the sustainable development of states and regions should be monitoring of the state of the natural environment and technosphere objects, as well as the organization of an anthropogenic, environmental, natural and territorial risk management system.

In addition to these aspects, the following points should be noted:

- an increased level of damaging effects at technosphere facilities located in climatic zones with low temperatures;

- unacceptably high level of depreciation of fixed assets and the exhaustion of design resources of machinery and equipment;

- low level of investment and, as a consequence, the impossibility of reconstruction and updating of fixed assets.

Awareness of the complexity of these problems has led to the need to develop national and regional scientific and technical policies in the field of safety of the population and national economic facilities. The main statements are formulated as follows:

1. The task of comprehensive safety support is a strategic task of the modern stage of industrial development.

(C) 2020 Copyright held by the author(s). Published by AIJR Publisher in "Abstracts of The Second Eurasian RISK-2020 Conference and Symposium" April 12- 19, 2020, Tbilisi, Georgia. Jointly organized by AMIR Technical Services LLC, Georgian Technical University, Institute of Geography (Kazakhstan) and Russian Institute of Petroleum Geology and Geophysics.

AijR DOI: $10.21467 /$ abstracts. 93 
The Second Eurasian RISK-2020 Conference and Symposium

2. Recognizing the priority of the safety problem over other problems of socio-economic development.

3. The main types of potential hazards (national-state, regional, natural-technological, environmental, economic, etc.) are in direct interaction and cannot be eliminated separately.

4. It is obligatory to adapt the legal regulation of the natural-technological safety requirements of the national level to the specifics of the functioning of the social-natural-technological sphere in regional conditions.

Information and regulatory support. To solve the indicated problems and tasks, the concept of socialnatural-technogenic (S-N-T) system (region, subject, municipality, industrial agglomeration) is used, for which the concept and structure of the information system of the territorial risk and safety management (ISTM RS “Region”) has been developed.

As part of the implementation of ISTM RS, the following results are presented:

- a unitary hardware-software complex for collecting, processing and analysis of network and remote monitoring data of individual elements of S-N-T systems, crisis databases and initial filling of the monitoring data warehouse;

- models and methods for assessing the risks of C-N-T systems, the nomenclature of basic risks and their normative level;

- technologies for creating maps of territorial risks of municipalities with ranking of territories according to the degree of technogenic danger.

- Risk assessment in the architecture of ISTM RS is carried out according to three modules - "Ecosphere", "Sociosphere" and "Technosphere", which is the basis for solving safety management tasks and forecasting sustainable regional development.

- Based on the results obtained, a "Guidelines for assessing the development risks of municipalities of social, natural and technological systems" has been developed to:

- maintain an acceptable risk level of the negative impact of dangerous factors on the population and the environment;

- provide information support for decision-making in the field of protecting the population and territories from natural and man-made emergencies.

The Guidelines is intended for expert risk assessment of the S-N-T system. The implementation of the developed recommendations allows us to give a comparative assessment of risks based on an analysis of all factors and dangers arising in the municipality territory. The document is a system of interconnected methodological materials that determine the procedure for assessing the risks of social-natural-technogenic systems. Risk analysis of S-N-T systems was carried out for a number of subjects of the Siberian Federal District and municipalities, taking into account the threats typical for these territories. The results obtained make it possible to formulate programs and activities aimed at reducing risk levels, and develop recommendations for improving the efficiency of territorial management. Risk reduction ensures more stable functioning of the economic potential and increases the competitive (investment) advantages of the region.

Funding: This work was funded by RussianFoundation for Basic Researches, Government of Krasnoyarsk Territory, Krasnoyarsk Regional Fund of Science, as part of the research project№ 18-47-240006 «Methods and informational technologies of social-natural-technogenic system risk assessment for industrial region». 